\title{
LA ASOMBROSA MARIONETA DEL EXTRANJERO ATENIENSE: DE LA IMAGEN A LA FILOSOFÍA EN LAS LEYES DE PLATÓN*
}

\author{
Diego García Rincón** \\ doi: 10.11144/Javeriana.uph36-73.amea
}

\section{RESUMEN}

Este ensayo sostiene que la estructura general de las Leyes de Platón obedece al principio de acceso indirecto al conocimiento del alma humana, que consiste en la comprensión de que la aproximación filosófica al alma solo es posible inicialmente a través de una imagen de ella. El decurso de las Leyes puede interpretarse como un movimiento hacia la interioridad del alma a partir de la famosa imagen de la marioneta, de acuerdo con la cual se comienza por analizar los elementos no-racionales del alma, capaces de conformarse en armonía con el elemento racional, y se avanza poco a poco hacia el elemento racional o epistémico. Solo al final del diálogo, con la fundación del Consejo Divino, aparece la necesidad política de emprender la investigación dialéctica para alcanzar un conocimiento filosófico del alma humana y de su excelencia específica. De este modo, el diálogo dramatiza el progresivo nacimiento de la filosofía, entendida como investigación dialéctica de la unidad de la virtud, a partir de la comprensión inicial del alma humana contenida en el mito de la marioneta.

Palabras clave: Platón; Leyes; alma; marioneta; imagen

En este artículo se exponen algunos temas tratados en el trabajo de grado titulado Moldear el alma con canciones: las Leyes como proemio a los diálogos de Platón. Agradezco al profesor Alfonso Flórez el diligente apoyo durante casi dos años en la elaboración de dicho trabajo.

* Universidad de Pisa, Pisa, Italia.

Correo electrónico: diegogr94@gmail.com

Para citar este artículo: García Rincón, D. (2019). La asombrosa marioneta del Extranjero Ateniense: de la imagen a la filosofía en las Leyes de Platón. Universitas Philosophica, 36(73), 121-146. ISSN 0120-5323, ISSN en línea 2346-2426. doi: 10.11144/Javeriana.uph36-73.amea 


\title{
THE ATHENIAN STRANGER'S MARVELOUS PUPPET: FROM IMAGE TO PHILOSOPHY IN PLATO'S LAWS
}

\begin{abstract}
This paper makes the claim that the overall structure of Plato's Laws follows the principle of indirect access to the knowledge of human soul, which consists in the understanding that a philosophical approach to the soul is only possible initially through an image of it. The structure of the Laws can be interpreted as a movement towards the soul's interior, beginning with the famous image of the puppet. According to this image, the movement opens with the analysis of the non-rational elements of the soul, which are capable of an harmonic relation with the rational element, and advances bit to bit to the rational or epistemic element. The political necessity of undertaking the dialectical investigation in order to attain a philosophical knowledge of the human soul and its specific excellence appears only at the end of the dialogue. In this way, the structure of the Laws dramatizes the progressive birth of philosophy, conceived as the dialectical investigation of the unity of virtue, starting from the initial understanding of the human soul contained in the myth of the puppet.
\end{abstract}

Keywords: Plato; Laws; soul; puppet; image 
Quien encontró el camino hacia adentro, quien en el ardiente hundirse en sí mismo presintió el núcleo de la sabiduría, de modo que su sentido elige a dios y al mundo sólo como imagen y como alegoría: cada acción y pensamiento dialogará con su propia alma, que contiene al mundo y a dios. Hermann Hesse, El camino hacia adentro

Si hay una constante que atraviesa los diálogos de Platón es que la aproximación a lo que en cada caso se investiga, dada la ocasión del encuentro dialógico, dados los caracteres de los interlocutores, se cumple siempre desde la perspectiva del alma humana ${ }^{1}$. La pregunta surge una y otra vez: ¿qué es eso mismo que buscamos ahora y qué poder tiene cuando se aloja en el alma de una mujer o de un hombre? La formulación doble de la pregunta, que interroga por el objeto y por su relación con nosotros, hace del alma misma el núcleo privilegiado de la reflexión en el contexto de los diálogos. En el caso de las Leyes, el misterioso interlocutor principal llamado Extranjero Ateniense concibe la política como el arte de cuidar (therapeúein) (Leyes 1, 650a) ${ }^{2}$ las almas de los ciudadanos con vistas a su excelencia, poniendo como primera tarea del político la de fijar su mirada sobre el carácter del alma (ệthos psuchệs theásasthai) (L. 1, 650a), para conocer la naturaleza y disposiciones de aquello cuyo cuidado se le encarga. La inmensa dificultad de la empresa del político está en el carácter particular del alma, cuyo conocimiento es bien diverso al que tenemos de las cosas del mundo, con lo cual la forma misma en que pueda alcanzarse tal conocimiento resulta uno de los problemas filosóficos centrales. La formulación insuperable es la de Sócrates en el Fedro, que señala la fuente de la dificultad a la vez que nos da el principio de su solución: "cómo es el alma, requeriría una larga y divina explicación;

1 Benardete (2000, p. xi) ha hecho de esta relación entre el ser y el alma, representada de modo distinto en cada diálogo platónico, el eje de su extensa interpretación de las Leyes.

2 En las referencias siguientes Leyes se abreviará como $L$., indicando siempre el libro al que pertenece la cita. 
pero decir a qué se parece, es ya asunto humano y, por supuesto, más breve" (246a). Definir el alma es cosa de dioses, mientras lo propio de la condición humana es acceder al conocimiento filosófico de sí misma a través de una imagen suya.

En este ensayo buscaré mostrar cómo se cumple la aproximación indirecta al alma a través de la imagen en las Leyes de Platón. Esta obra se inaugura en cierto modo con el famoso mito de la marioneta, imagen del alma humana situada al final del primero de los doce libros del diálogo, posición que indica su función como puerta de entrada al conjunto de la obra (Voegelin, 2000, p. 287). Fiel al proceder del texto, iniciaré por el análisis de la imagen mítica de la marioneta, en la cual el Extranjero Ateniense descompone la dinámica del alma humana en sus movimientos elementales: placeres, dolores y razonamiento. Argumentaré que los movimientos no-racionales del alma se caracterizan por su esencial plasticidad, la capacidad que tienen de adquirir configuraciones diversas según su disposición nativa, las costumbres en que están inmersos y la formación que reciben. Dado que en las Leyes se concibe la excelencia humana como armonía entre los diversos elementos del alma, el paradigma al que apunta la formación de lo no-racional, en cuanto que se busca plasmar orden y estructura en la dinámica anímica, se encuentra en el elemento racional del alma. Por ello, el examen de los elementos anímicos noracionales es una tarea que exige el paso al examen del elemento racional. Por medio del recurso al libro 10, entonces, precisaré los movimientos anímicos que se caracterizan por su contenido epistémico y que le confieren al alma su capacidad de informar lo no-racional o, en términos del propio libro 10, gobernar el cuerpo. Esto completará un cuadro a grandes rasgos de la concepción del alma humana con la cual opera el Extranjero Ateniense a lo largo de las Leyes.

Aunque el movimiento hacia el conocimiento del alma comience de modo indirecto en la imagen, no se agota en ella. Por esto, sobre la base de la concepción del alma contenida en el mito de la marioneta y para mostrar cómo, en el desarrollo dramático del diálogo, el mito suscita el movimiento filosófico, habrá que pasar al examen de la parte final del último libro del diálogo. En este se discute la institución del Consejo Divino, órgano político que tiene como función principal la 
investigación de la unidad de la virtud ${ }^{3}$ por medio de la dialéctica, investigación orientada a asegurar la persistencia en el tiempo del régimen político. La lectura de este pasaje me llevará a preguntar por qué la investigación socrática de la unidad de la virtud aparece en el libro final del diálogo y no antes.

Reconociendo en la investigación dialéctica de la virtud humana una manifestación principal de la filosofía en el corpus platónico y no un mero vestigio socrático relevante solo en las primeras obras de Platón y abandonado luego en las obras de madurez, la cuestión surgida de la lectura de este pasaje deberá formularse así: ¿por qué la filosofía misma aparece tan solo al final de las Leyes?, ¿cuál es el lugar de la filosofía en las Leyes? ${ }^{4}$ Ofreceré una respuesta tentativa a estas preguntas, que consistirá en una interpretación del movimiento total de las Leyes, desde el primer libro hasta el último, como una invitación a penetrar la imagen poética del alma humana contenida en el mito de la marioneta, superándola por medio de la investigación dialéctica de la unidad de la virtud, esto es, por medio de la filosofía.

\section{La lucha de las fuerzas opuestas dentro de la marioneta}

Para tener ante la vista todo el pasaje cuyo sentido se elaborará a continuación y por la belleza de la imagen, vale la pena extenderse citando el mito de la marioneta:

3 'Excelencia' es una traducción más fiel del término griego areté (como ha mostrado etimológicamente Massetti, 2013/2014, p. 124). He mantenido la traducción tradicional en las citas para no modificar sistemáticamente el texto en español de Pabón \& Fernández-Galiano (1992) pero, en ocasiones, usaré la palabra excelencia.

4 Una corriente joven, aunque de estirpe antigua, de la interpretación de Platón ha defendido que el único criterio hermenéutico válido para la comprensión de los diálogos se encuentra en los diálogos mismos. En consecuencia, Zuckert (2009) organiza el conjunto de los diálogos a partir de la fecha dramática implícita en cada uno de ellos, y Altman (2012) considera que el empeño pedagógico de toda la obra de Platón, con la República como enseñanza central, da forma a lo que él llama "el orden de lectura de los diálogos". Estas posiciones operan de facto una puesta en cuestión de la interpretación del corpus a partir de la supuesta fecha de composición de los diálogos, criterio externo a estos. Así queda legitimado el recurso a los diálogos que tienen a Sócrates como interlocutor principal en la interpretación de las Leyes. En lo que respecta a este ensayo, ello es de importancia porque permite interpretar la institución del Consejo Divino en las Leyes como el surgimiento en Magnesia de la filosofía socrática. 
Pensemos que cada uno de nosotros, los seres vivos, somos marionetas de los dioses, fabricados ya para juguetes de ellos, ya con algún fin serio, pues esto último, en efecto, no lo conocemos: lo que sabemos es que esas afecciones (páthe ), a manera de unas cuerdas o hilos interiores, tiran de nosotros y nos arrastran, siendo opuestas entre sí a acciones opuestas en la línea divisoria de la virtud y la maldad. En efecto, la razón (lógos) nos dice que debemos seguir constantemente una sola de aquellas tensiones y, sin dejarla en manera alguna, tirar contra las otras cuerdas; y que esa tensión es la conducción del raciocinio (logismồ), áurea y sagrada, que se llama ley general de la ciudad; que las otras son duras y férreas, y solo aquella suave y uniforme como el oro, a diferencia de las demás, multiformes con varias apariencias. Hay, en verdad, que ayudar constantemente a esa hermosísima conducción de la ley, pues siendo el raciocinio en su belleza blando y no violento, necesita de quien sirva a su impulso para que lo que es de oro venza en nosotros a lo que es de otras materias. Y así podría mantenerse el mito de la virtud en que nosotros somos marionetas, y quedaría de algún modo más claro lo que significa ser superior y ser inferior a sí mismo; e igualmente que, en lo que toca al individuo y a la ciudad, el primero, tomando en sí razón verdadera de estas tensiones, debe vivir conforme a esta razón; y la segunda, que ha recibido ese mismo concepto (lógon) ya de algún dios, ya de un hombre conocedor de estas cosas, ha de establecerlo como ley para sus relaciones consigo misma y con las otras ciudades (L.1, 644d-645b).

El mito plantea el doble problema en que se encuentra la marioneta. Por un lado, ella padece una incertidumbre sobre su propio valor, sobre sus fines; por el otro, está dividida entre las fuerzas contradictorias que aloja en su interior ${ }^{5}$. La ignorancia de sí pone a la marioneta en la frustrante incapacidad de determinar en qué sentido debería dirigir sus acciones para apaciguar su lucha interna. Pero la incertidumbre de la marioneta es resultado de la dinámica que la constituye. A pesar de la ignorancia y de la lucha interna que sufre, la marioneta puede observar y expresar la forma de su propio movimiento, tal como este aparece en medio

5 El carácter interno de la lucha de las tensiones representadas por los hilos de la marioneta encuentra una argumentación detallada en Sassi (2008, pp. 129 y 139), que expresa la lucha en términos de "conflicto psicológico". 
de la confusión que el mito nos presenta. Los elementos que se conjugan en este movimiento complejo de la marioneta son sus afecciones o pasiones (páthe ), representadas como hilos, lo que indica que ejercen fuerza sobre la marioneta y muchas veces pueden incluso arrastrarla. La situación que se muestra en el mito es, pues, dinámica. No podía ser de otro modo, al tratarse de la interacción de las tensiones que constituyen lo anímico, tensiones que luchan las unas con las otras y se suman para dar un movimiento resultante que siempre se conforma a partir de una multiplicidad de elementos. ¿Cuáles son estas tensiones y cómo se relacionan entre sí?

Los hilos férreos de la marioneta son los "placeres y dolores (hẹdonás kai lípas)", "dos fuentes que manan y corren por naturaleza” en el alma y en la ciudad $(L .1,636 \mathrm{~d})$ y que el mito nos presenta como opuestas y contrarias las unas a las otras. En el sentido más evidente, se dice que el placer y el dolor tiran en direcciones opuestas porque el placer nos invita a tomar el objeto entre manos, mientras el dolor nos hace retroceder ante él. Pero la cuestión se complica cuando el placer y el dolor se combinan en situaciones en las que ya no se puede explicar el movimiento anímico ateniéndose tan solo a una sensación que somete a las demás. Un objeto placentero puede hacerse accesible en una situación de peligro, por ejemplo, combinando el deseo de satisfacción con el miedo del castigo.

La explicación anterior es válida siempre que la expresión placeres y dolores se entienda como referente a "sensaciones" (aisthesin) (L. 2, 653a) de placer y de dolor. Así la usan a veces el Extranjero Ateniense y Megilo, uno de los dos interlocutores del Extranjero. Megilo habla de dolores tales como "andar descalzo y no tener lecho en invierno" (L. 1, 633b); el Extranjero habla de "los más grandes placeres y diversiones", de fiestas, entretenimientos y deleites (L. 1, 635b-d). Pero este no es el único uso que el Extranjero le da a la expresión. Esto se nota en el hecho de que las anticipaciones respectivas, el miedo y el atrevimiento, que se refieren a objetos futuros, estén designadas algunas veces por medio de la expresión $(L .1,644 c)$. En sentido amplio, incluso el odio está englobado en los "dolores" (L. 2, 653c), mientras los "placeres" incluyen el apetito y el amor (L. 1, 643c-d), el deseo y la seducción ( $L .1,633 \mathrm{~d})$. Así entendida, la expresión placeres $y$ dolores denota un campo fenoménico bastante amplio y resulta ser "la categoría general de la motivación no-racional” (Sauvé-Meyer, 2015, pp. 174-175). Para 
nombrar la riqueza de los componentes no-racionales de la vida anímica, el Extranjero usa la expresión en este sentido amplio.

La expresión no-racional difiere de la más usual irracional en un sentido importante y pide una aclaración. La primera no conlleva, como la segunda, una valoración negativa de los fenómenos en cuestión, sino tan solo su alteridad en relación con lo racional. Lo no-racional se define como aquello a lo que no le es propio y necesario tener estructura y medida, pero que, con la formación adecuada, puede llegar a moverse en armonía con lo racional. Mostrar que, en las Leyes, lo no-racional no es un estrato anímico que deba ser reprimido o despreciado, como han solido pensar muchos intérpretes de Platón ya desde Plotino, es un objetivo secundario de este ensayo.

El Extranjero Ateniense justifica el esfuerzo que pone en comprender las tensiones no-racionales del alma humana por el lugar fundamental que estas ocupan en la vida política: "cuando los hombres investigan acerca de las leyes, casi todo su examen tiene por objeto los placeres y los dolores que se dan en las ciudades y en la vida de los individuos" ( $L .1,636 \mathrm{~d})$. El hecho es que lo no-racional posee un poder ambiguo; puede tanto enseñar y ennoblecer como seducir y corromper a los individuos y a las ciudades. El problema, común pero persistente, que el legislador encuentra en estas afecciones del alma es que la mayoría de los seres humanos se ven arrastrados por ellas a la desmesura y al hedonismo vulgar con demasiada facilidad ${ }^{6}$. En vista de esta situación, el legislador platónico no condena los hilos no-racionales de la marioneta, sino que busca inculcar la disposición para un uso de ellos que no la desgarre:

bebiendo la debida cantidad en el lugar y tiempo que procede, resulta feliz lo mismo la ciudad que el individuo y, en general, todo ser; y el que la bebe sin conocimiento (anepistemónoss) y fuera de sazón lleva existencia enteramente opuesta a la de aquel (L. 1, 636d-e).

6 Jorgenson (2018, pp. 39-42, 47-52) argumenta que el centro de los varios argumentos que Platón esgrime para desviar al hedonista de la búsqueda desmesurada de placer es la capacidad que este tiene de causar conflicto entre las partes del alma, hasta tal punto que ella se enfrenta violentamente consigo misma, causándose muchas más sensaciones de dolor que de placer. La búsqueda excesiva de placer es "autodestructiva" (self-defeating). 
La diferencia entre quien bebe de las fuentes con medida y quien no lo hace está en un componente epistémico, prudencial. Con esto aparece el elemento restante que se cuenta entre las afecciones del alma, el hilo de oro del razonamiento. La marioneta representa el alma de un ser humano en su constitución adulta íntegra. Las afecciones engloban todo lo que acontece en el alma, comprendiendo tanto lo que hace como lo que padece, conjunto de experiencias que se completa ahora con el hilo de oro y que puede recogerse en la expresión placeres, dolores y razonamiento.

Es difícil determinar con exactitud a qué se refiere el Extranjero Ateniense con el término razonamiento (logismós). En el uso común de la lengua griega, el sentido primario de la palabra es el de cálculo, es decir, el proceso realizado en las operaciones aritméticas. Si se le quita la referencia exclusiva al número, el término pasa a nombrar la operación de calcular en general, que puede llamarse razonamiento, en el sentido de un razonamiento. Un tercer sentido es el resultado del razonamiento, el veredicto o decreto (dógma) (L. 1, 644d). En un cuarto y último sentido, el término puede significar la facultad del alma que realiza el cálculo en cuestión, la razón ${ }^{7}$.

La cuestión se esclarece al observar que los placeres se oponen a los dolores "en la línea divisoria de la virtud y la maldad" ( $L$. 1, 644e). El cálculo de la marioneta tiene por contenido el bien y el mal en las acciones. Justo antes del mito de la marioneta, en efecto, aparecen los placeres y dolores en sentido amplio y "sobre todos ellos un cálculo (logismós) de lo que de estas cosas es mejor o peor" (L. 1,644d). El razonamiento es, por tanto, el proceso que el alma realiza durante la lucha de sus hilos no-racionales, proceso que discrimina el bien y el mal de aquello a lo que empujan placeres y dolores. Ahora bien, el razonamiento, "cuando se hace decreto general en la ciudad, es llamado ley" (L. 1, 644d). Hay, pues, una diferencia entre el proceso mismo y su resultado, que se ha vuelto decreto. El decreto es el razonamiento que, expresado en la palabra, ha quedado cristalizado en la ley general de la ciudad. Por último, que sea relevante postular, en este punto de la argumentación, una facultad del alma que lleve a cabo el proceso del razonamiento no es evidente a partir del texto.

7 Así traducen y explican el pasaje Brisson y Pradeau (2006, p. 101). 
Lo cierto es que el razonamiento calcula y juzga lo relativo al bien y el mal en las acciones, dándole valor moral a las inclinaciones de los movimientos noracionales del alma ${ }^{8}$. Con esta explicación se comprende mejor por qué los placeres y dolores se representan como sensaciones que, consideradas en sí mismas, son ciegas. Ellas arrastran al alma, pero no pueden dar razón del bien y el mal de las acciones a las que arrastran. De esta situación surge la pregunta por la posibilidad de orientar estas fuerzas mediante aquella parte del alma que es capaz de discernir lo mejor. Pero, a pesar de su poder de dilucidar el bien y el mal en las acciones, el razonamiento es un hilo entre los otros que hay en la marioneta y entra sin preeminencia en el juego de fuerzas que luchan en el alma. La naturaleza áurea y sagrada del razonamiento parece asegurar de antemano que su conducción gobernará la marioneta, pero las otras cuerdas son duras y férreas y arrastran al alma hacia sus objetos o la apartan de estos, sin importar lo que el razonamiento señale como mejor. La naturaleza suave del razonamiento implica que este no tiene la potencia necesaria para vencer en la lucha anímica por sí mismo.

Va perfilándose con mayor nitidez la difícil situación en la que se encuentra la marioneta. Por un lado, placeres y dolores luchan por arrastrarla en direcciones opuestas; por el otro, calcula mediante el razonamiento sobre el bien y el mal de aquello a lo que se siente impulsada; habiendo reconocido lo mejor, sin embargo, muchas veces carece de fuerza para vencer las partes más potentes de sí misma. En suma, la marioneta se encuentra en una batalla consigo misma. Se trata de una guerra civil, interna, en la cual una o más facciones del alma se revelan contra las demás y luchan por cumplir sus designios particulares, tiranizando el alma entera sin considerar si sus determinaciones propias las han destinado al gobierno de la ciudad interior o no. Según el mito, en esta batalla la marioneta debe ayudar a la conducción del razonamiento, sirviendo a su impulso sin abandonarse a los jalones férreos de las tensiones no-racionales. Tiene que encontrarse, entonces, alguna forma de poner los duros metales férreos de la marioneta al servicio del elemento áureo, de forma que todos alcancen una operación conjunta armoniosa. Si esta meta ha de ser siquiera concebible, los

8 Frede (2010, p. 119) da cuenta de esta función del razonamiento suponiendo que todas las fuerzas de la lucha anímica son no-racionales, dado que el razonamiento no es una fuerza en sentido propio, sino la capacidad de dar forma y valor moral a las fuerzas no-racionales. 
placeres y dolores deben ser modificables, orientables a objetos distintos. Mientras mantengan la dureza propia del hierro, seguirán sometiendo a la marioneta a acciones que solo con mucho trabajo y penuria podrá evitar.

\section{La plasticidad de los movimientos no-racionales del alma}

Puede afirmarse sin exagerar que casi todo el sistema educativo de Magnesia es una respuesta al problema de la educación de los movimientos no-racional del alma. Ello se muestra en la función que el Extranjero Ateniense le da al vino en Magnesia, la ciudad instituida en la palabra. Si el vino se bebe en ciertas condiciones, además de mostrar los caracteres y las inclinaciones no-racionales de cada uno, al eliminar gradualmente sus inhibiciones racionales, pone a los ciudadanos en un estado que permite moldearlos. Esto tenía que resultar escandaloso para Megilo, ciudadano de Esparta, donde el vino estaba prohibido y era visto como uno de los peores enemigos de quien aspiraba a ser un guerrero excelente. El Extranjero, en cambio, fiel a su espíritu ateniense, observa con agudeza que el vino actúa

de tal modo que nos rejuvenecemos por él por el olvido de la pesadumbre, y se ablanda el carácter de nuestra alma dejando su dureza como el hierro que, puesto al fuego, se regala y hace más dúctil (euplastóteron) (L. 2, 666b-c).

La mención del hierro en este pasaje hace referencia a su aparición como material de los hilos no-racionales en el mito de la marioneta ( $L$. 1, 645a). También refieren al mito las palabras que describen el carácter como algo que, siendo duro, se vuelve más blando por el efecto del vino, pues los hilos de hierro de la marioneta fueron llamados duros, mientras la conducción del hilo de oro fue llamada suave. Estos paralelismos textuales entre el mito de la marioneta, que contiene la semilla del sistema educativo de Magnesia, y el presente pasaje indican que la acción suavizadora del vino, a través de la cual el legislador propone plasmar forma en los caracteres, es un símbolo de la acción del sistema educativo entero.

El medio definitivo que el Extranjero Ateniense instituirá para informar lo no-racional del alma es la música, en su amplitud griega de poesía, danza y canto, dado el efecto formativo que el estructurado devenir de los movimientos musicales 
tiene sobre la estructura dinámica del alma9. Pero más allá del medio particular que elija cada educador ateniéndose a las condiciones en las que deba educar, su acción se basa siempre sobre el hecho de que la capacidad de modificar lo no-racional por medio de un tipo específico de educación es una condición estructural del alma, condición que se revela con claridad paradigmática gracias a la eficacia del vino. Si se presta atención a la raíz de la palabra final que habla del estado del hierro que ha sido puesto al fuego, esta condición del alma puede llamarse plástica, pues el hierro caliente se vuelve más plástico (euplastóteron), más receptivo de la forma que quiere plasmarse en él, más capaz de ser forjado e informado (L. 2, 671c).

Que la concepción plástica del alma es un supuesto operativo que subyace al texto entero de las Leyes, se confirma cuando el Extranjero habla de la multiplicidad de costumbres que ha resultado en el devenir de la historia humana:

formaciones y ruinas de ciudades, y costumbres de toda especie en punto a orden o a desorden, y apetitos de los más diversos por lo que toca a la manera de comer o aun a bebidas y alimentos, eno creemos que de esto ha habido siempre en la tierra entera, así como toda clase de trastornos en las estaciones, durante los cuales es natural que los organismos hayan sufrido en sí mismos un sin fin de cambios? (L. 6, 782a)

La plasticidad más evidente se muestra en los cambios de las costumbres relativas a la satisfacción de los apetitos, cambios que consisten en la variación de los objetos apetecidos. Pero las costumbres y asuntos humanos son moldeables en un sentido más profundo que el mero cambio en el objeto del deseo. Ello se advierte en la controversial propuesta que el Extranjero hace a sus interlocutores de que las mujeres aprendan "a cabalgar y servirse de dardos, jabalinas y hondas" (L. 7,794c), incluso que aprendan a manejar las armas pesadas. La razón de la propuesta es que no hay una diferencia natural entre los géneros que exija que sus costumbres deban ser diferentes, por lo menos en este registro educativo ${ }^{10}$. Lo

9 De modo brillante, Prauscello (2013, pp. 258 y 261) defiende que la estructura temporal de la música, sobre todo de la lírica coral, es el fundamento del condicionamiento de las respuestas morales futuras de los ciudadanos.

10 Toda la sección $L .7,806 \mathrm{~d}-808$ c está dedicada a esta cuestión, en líneas que recuerdan la "primera oleada de la argumentación" en República 5, 451d-457e. 
mismo ocurre con las manos. Suele pensarse que se nace diestro o zurdo, cuando en realidad la mayoría se engaña "en creer que nuestra derecha y nuestra izquierda son por naturaleza (phýsei) diferentes en relación con las diversas actividades de las manos" ( $L .7,794 \mathrm{~d})$, y es esta ignorancia lo que impide educar para la habilidad del ambidextro. Todo esto revela que la plasticidad está pensada en las Leyes como una capacidad propia del alma humana en relación con la totalidad de lo que ella puede aprender o desaprender por medio del hábito, sobre todo en relación con sus movimientos no-racionales y con la esfera de lo que está determinado por el cuerpo. Lo natural en el alma vendría a ser entonces la capacidad que ella tiene para el cambio de la costumbre en general.

La potencia adaptativa y plástica del alma lleva en sí una exigencia de formación. Lo que la marioneta entiende cuando vuelve su mirada sobre sí misma para examinar su propia dinámica es que mucho de lo que sucede en ella está en sus propias manos y puede modificarse y mejorarse de acuerdo con lo revelado por la guía del hilo áureo. El afán del legislador griego de plasmar una forma en la materia anímica responde a la naturaleza plástica de lo no-racional. No se trata de suprimir la naturaleza, de usar la fuerza del Estado para imponer al individuo una disciplina artificial ${ }^{11}$. En la concepción platónica, la educación no le hace violencia a la naturaleza en el sentido de doblegarla para imponer un orden externo. Para confirmarlo, baste recordar que el prisionero de la caverna es liberado de sus cadenas "de acuerdo con lo que es natural (phýsei)" (República 7, 515c) ${ }^{12}$. Lo humano es a un tiempo naturaleza y ley, y es difícil o imposible fijar la línea que separa ambos componentes.

La importancia de pensar el modo de estructurar la dinámica de las tensiones no-racionales del alma se debe a que "las primeras y tiernas sensaciones de los niños son el placer y el dolor" (L. 2, 653a) y de que es a través de ellas como "llegan en un principio al alma la virtud y el vicio" ( L. 2, 653a). El carácter del alma se empieza a formar apenas los movimientos no-racionales aparecen en ella. Resulta así central la formación "que se da primeramente en los niños: cuando el placer

11 Es la interpretación de Russon (2013, p. 66).

12 Vergara (1988, p. 157) introduce este argumento en el contexto más amplio de la educación griega en general, caracterizada por su sostenido afán de moldear seres humanos bellos y buenos. 
y el amor, el dolor y el odio se producen rectamente en sus almas sin que puedan aun razonar sobre ello" (L. 2, 653b). Esta formación ocupa el tiempo en que los niños todavía no son capaces de aprehender las razones que la fundamentan, razones que no son otras que el texto mismo de la ley.

En el marco de la vida ciudadana de Magnesia, ni siquiera es necesario que el ciudadano adulto llegue a desarrollar la capacidad racional: "en cuanto a la razón y a la opinión verdadera, ya tiene buena suerte aquel a quien llegan, aunque sea en la vejez" (L. 2, 653a). Por eso la crítica ha insistido en que el sistema educativo de Magnesia opera en un nivel anterior al desarrollo intelectual en sentido propio ${ }^{13}$. La educación de los elementos no-racionales no apunta tanto a que el individuo llegue a la comprensión de sus costumbres, como a que esas costumbres se den en armonía con el razonamiento todavía no desarrollado en ellos, pero cristalizado por el legislador de una vez por todas en el texto de la ley.

\section{El gobierno del componente epistémico sobre lo no-racional}

\section{EL HECHO DE QUE, INCLUSO EN UN SISTEMA EDUCATIVO FUNCIONAL COMO} el de Magnesia, y quizás por meras razones estadísticas, solo pocos ciudadanos sean capaces de desarrollar el uso del razonamiento, no debe llevarnos a afirmar que para el Extranjero Ateniense dicho desarrollo no es importante y deseable en la vida humana. En realidad, el ideal de excelencia del Extranjero culmina con tal desarrollo racional:

cuando, alcanzando ya a razonar (labónton de ton lógon), todo eso [lo noracional del alma] se armoniza con su raciocinio (tối lógói) en reconocer la rectitud de las costumbres creadas por el hábito conveniente, esa armonía es la virtud completa (he sumfonia súmpasa areté) (L. 2, 653b).

La capacidad racional es necesaria en el ciudadano ideal porque la excelencia completa no consiste en la mera repetición del hábito o de lo prescrito por el legislador, sino que llama a un ejercicio racional que acompañe el actuar del

13 Por ejemplo, dice Klosko (2006): "el sistema necesario de educación opera generalmente en un nivel bajo, condicionando actitudes respecto al placer y el dolor en lugar de desarrollar el intelecto" (p. 219; traducción propia). ["the necessary system of education generally operates on a low level, conditioning attitudes towards pleasure and pain rather more than developing the intellect."] 
ciudadano y le permita justificar sus decisiones, anclándolas en la palabra. En esta armonía y reconocimiento de la familiaridad entre lo no-racional y lo racional está la excelencia humana completa, tal como se concibe en las Leyes.

Según el desarrollo educativo ideal del ciudadano de Magnesia, entonces, la formación de los plásticos elementos no-racionales por medio de la música, esbozada en su posibilidad en los dos apartados anteriores, se culmina en el ejercicio del razonamiento, con cuyo examen debe proseguir ahora el presente discurso. Con este fin, es necesario abordar la argumentación del libro 10 de las Leyes, donde aparecen por vez primera en el diálogo los movimientos epistémicos del alma. Como se verá, son estos movimientos los que posibilitan la función de gobierno que el alma ejerce, desde su elemento racional, sobre los elementos noracionales, razón por la cual dichos movimientos son el fundamento último del proyecto político-educativo del Extranjero Ateniense.

Pues bien, en el libro 10 de las Leyes se expone la concepción del alma como primaria en relación con el cuerpo, según la cual el alma nace "entre los seres primarios y es anterior a los cuerpos todos y gobierna (árchei) capitalmente todo cambio y toda nueva ordenación de ellos" $(L .10,892 \mathrm{a})^{14}$. Se trata de una primacía ontológica y no temporal del alma, primacía que se debe al tipo de movimiento que la caracteriza y a partir del cual ella se define, pues alma es aquello que puede "perpetuamente moverse a sí mismo y a las otras cosas por mezclas y separaciones, aumentos y disminuciones, generaciones y destrucciones" (L. 10, 894b; véase también Fedro $245 \mathrm{c}-\mathrm{d}$ y Timeo $47 \mathrm{e}-53 \mathrm{a})^{15}$. En contraste con el

14 El lugar central del alma en el libro10 ha sido defendido por Schöpsdau (2011) y Flórez (2012, p. 12). La mayoría de los intérpretes han visto el libro 10 como el tratado que desarrolla la doctrina teológica de Platón en líneas similares a las del Timeo (Mayhew, 2008, pp. 1-10), mientras algunos han enfatizado su función persuasiva (Lin, 2016, p. 192; Fossheim, 2013, p. 94). En uno y otro caso, aunque no siempre de forma explícita, el alma se encuentra en el centro de la cuestión, como fundamento de la argumentación sobre los dioses o como receptora de la fuerza persuasiva de dicha argumentación.

15 Schöpsdau (2011, p. 270) llama "Vorrang" a la primacía, palabra que quiere decir literalmente 'rango anterior' y que da a entender una superioridad política, un cargo más alto en el gobierno de la ciudad, así como la preeminencia de los ciudadanos mayores sobre los más jóvenes que rige en Magnesia. A pesar de las semejanzas entre esta argumentación de las Leyes y algunas secciones del Timeo, la relación entre ambos diálogos es particularmente espinosa en este punto. Para una 
automovimiento del alma, el cuerpo se define como aquello que siempre es movido por otro (L. 10, 893b-894a).

Como consecuencia del planteamiento de la cuestión en términos de los tipos de movimiento, el argumento principal a favor de la tesis de la primacía ontológica del alma en relación con el cuerpo se basa en una comparación entre el automovimiento propio de aquella y el ser movido por otro, propio de este, comparación que reduce el ser movido por otro, necesariamente, al automovimiento (L. 10, 894e-895a). Es imposible que la cadena de cuerpos, movidos por otro, se extienda hasta el infinito, necesidad del pensamiento que lleva a constatar que el alma es aquello que se mueve a sí mismo y constituye el principio del movimiento físico. Abreviando la cuestión, decir que el alma gobierna al cuerpo es decir que la potencia propia del alma consiste en que ella es capaz de moverse a sí misma.

Debido a los límites del presente ensayo, no es posible entrar en los detalles de la argumentación del libro 10. Quisiera tan solo llamar la atención sobre el hecho de que la defensa de la primacía ontológica del alma sobre el cuerpo se traduce en un gobierno del alma sobre el cuerpo, que solo es comprensible si el alma tiene en sí un componente de visión epistémica, capaz de dirigir el cuerpo con conocimiento de los fines de su movimiento. Si leemos esta comprensión general sobre la base de lo analizado en el mito de la marioneta, resulta que el alma es capaz de gobernar el cuerpo porque en ella opera el hilo áureo del razonamiento, elemento que le brinda orientación a las tensiones no-racionales. En este contexto cobra sentido pleno la enumeración de los movimientos del alma que el Extranjero ofrece en el libro 10, donde lo que hasta ahora se había llamado tan solo placeres, dolores y razonamiento alcanza su diferenciación plena: "querer, considerar, prevenir, deliberar, opinar recta o falsamente, alegrarse, dolerse, confiar, temer, odiar, amar" (L. 10, 897a).

Además de los movimientos no-racionales, aparecen ahora los movimientos del alma que se caracterizan por su contenido epistémico: querer, considerar, prevenir, deliberar y opinar. Estos movimientos estaban implícitos en la actividad misma de legislar que el Extranjero ha realizado a lo largo del diálogo,

discusión de "la teoría platónica de las causas" (die platonische Theorie der Ursachen) del Timeo en relación con el automovimiento del alma en varios diálogos, véase Schöpsdau (2011, p. 412). 
pero solo ahora se hacen explícitos. Sin embargo, frente a esta aparición de lo epistémico y más allá de su valor inmediato en el libro 10 como parte de la argumentación sobre la primacía del alma sobre el cuerpo, el lector de las Leyes queda un tanto desorientado, pues esta se da en el antepenúltimo libro de la obra, después de que se ha dedicado casi la totalidad de los nueve libros anteriores a la legislación de lo no-racional del alma, con la única excepción de la discusión sobre la educación literaria (7, 809e-812b). El mismo libro 10 ocupa un lugar a primera vista desigual en el conjunto de las Leyes. La razón es que no hay muchos elementos en el diálogo para enriquecer la interpretación sobre el lugar que los movimientos epistémicos ocupan en este. Lo que más extraña del pasaje es que no hay ningún individuo ni institución en Magnesia cuya función sea ejercitar la esfera epistémica de los movimientos del alma humana. Es cierto que la legislación constituye la presencia principal del razonamiento en Magnesia, orientando la vida política ${ }^{16}$, pero los ciudadanos mismos carecen de esos movimientos epistémicos en virtud de los cuales el alma gobierna sobre el cuerpo.

La consecuencia inmediata de la falta de la práctica, tanto colegiada como individual, de los movimientos epistémicos del alma es que Magnesia no puede asegurar su propia "preservación" (soterían) (L. 12, 960d), pues como las leyes mismas son incapaces de responder a las contingencias de la vida política, no hay en la ciudad un elemento de visión epistémica activa que vele por su propio mantenimiento en el tiempo. A pesar de tener la apariencia de estar constituida por completo, a Magnesia le faltan todavía los "preservadores de las leyes" (sotêres nómon) $(L .6,770 \mathrm{~b})$ en sentido propio, aquellos capaces de investigar lo que en cada caso es mejor para la supervivencia del régimen. Mientras no se solucione esta situación, Magnesia está incompleta, sin finalizar (atéles) ( $L .12,960 \mathrm{c})$, y se asemeja a un animal sin cabeza ni ojos, a un alma sin intelecto ( $L .12,961 \mathrm{~d}-\mathrm{e})$, incapaz de devolver el sentido a su propio movimiento cuando este enferma y se vuelve errático.

Frente a esta dificultad que surge en el último libro del diálogo, la respuesta del Extranjero Ateniense es la institución del Consejo Divino (theîos súllogos) (L. 12, 969b), órgano que deberá velar por la preservación en el tiempo del

16 Voegelin (2000, pp. 316-317) ve en la ley el símbolo que media la distancia entre el razonamiento divino y la escasa potencia existencial de los ciudadanos de Magnesia. 
régimen político. Las actividades que lo caracterizan y en virtud de las cuales puede desempeñar esta función, sin embargo, no son claras a partir de los once primeros libros de las Leyes. Sabemos que el Consejo deberá desarrollar los movimientos epistémicos que le permiten al alma gobernar sobre el cuerpo, pero la forma concreta de esta actividad no se ha manifestado hasta ahora en el diálogo. La consideración de este estado de cosas nos pondrá frente a la súbita aparición de la filosofía socrática en Magnesia.

\section{El Consejo Divino y la investigación dialéctica de la unidad de la virtud}

El desempeño efectivo de las funciones del Consejo Divino depende de una investigación que el Extranjero Ateniense no había previsto hasta el final de las Leyes y que él mismo no ha emprendido todavía. Quien se propone preservar y perfeccionar las leyes tiene que entender qué es la virtud humana, que, según la reiterada convicción del Extranjero, es el fin al que apunta toda legislación. De este modo, el problema central del Consejo Divino viene a coincidir con la pregunta socrática por la unidad de la virtud:

también a los guardianes de nuestro sistema político divino, así parece, debemos obligarlos a ver exactamente, primero, qué es lo mismo a través de todas las cuatro virtudes, a lo que decimos que, por encontrarse como uno en la valentía, templanza y justicia y también en la inteligencia, podríamos darle con razón el nombre de virtud (L. 12, 965c-e).

No se puede leer este sorprendente pasaje sin preguntarse qué relación pueda tener el Consejo Divino con la figura de Sócrates, que formula su propio quehacer en términos casi idénticos ${ }^{17}$. La reminiscencia socrática incrementa cuando el Extranjero afirma que la investigación proyectada necesita de una educación "con un grado de exactitud superior" a la diseñada por él, que capacite al preservador de las leyes para discernir la unidad en la idea a partir de una multiplicidad (pros mían idéan ek tôn pollôn) (L. 12, 965c). Este aprendizaje superior es

17 Lugares clásicos de la pregunta socrática que resuenan con este pasaje son Protágoras (349a-d) y Menón (70a-79e). 
la dialéctica, "el método más seguro" (safestéra méthodos) $(L .12,965 \mathrm{c})$ para la investigación de la excelencia humana. Además, el Consejo investigará lo bueno, lo bello, lo divino, el alma y la relación que la música tiene con ella. Si se considera la investigación socrática de la unidad de la virtud, con todas sus ramificaciones, como el símbolo principal de la filosofía en los diálogos de Platón, lo que presenciamos al final de las Leyes es que el Extranjero Ateniense comprende que el órgano más alto de su ciudad deberá emprender el camino de los estudios filosóficos para investigar el alma humana.

Dada la importancia de la tarea del Consejo Divino para la conservación del cuerpo político y dado el lugar que la investigación filosófica tiene en esta, es difícil explicar por qué la palabra filosofía y sus cognados están casi ausentes en el texto del diálogo. La primera aparición de la palabra se da en el libro 9. Ahí se dice que un médico libre que tratara a un hombre libre dialogando con él y buscando el principio de su enfermedad por medio de la palabra, llegaría casi a filosofar con el discurso (tố filosofeîn eggus chrómenon men toîs lógois) (L. 9, 857 d), como si estuviera educando al enfermo en lugar de curarlo. El contexto médico de la primera aparición de la filosofía es revelador porque este tratamiento médico por medio del lógos, único ámbito en el cual puede descubrirse el principio de una enfermedad, resuena con la tarea del político formulada por el Extranjero como "cuidar" (therapeúein) (L. 1, 650a) las almas de los ciudadanos. Queda así implicado un vínculo entre la política, la medicina y la filosofía, tres actividades orientadas al cuidado del alma y del cuerpo. Pero de la filosofía en sentido propio, fuera de esta sugestiva mención metafórica, no se dice nada hasta la institución del Consejo Divino (L. 12, 960c-969d). ¿Cómo debe entenderse esta ausencia textual?

La singular ausencia de la palabra filosofía casi en todo este diálogo se debe a una deficiencia en la concepción del alma sobre la cual este opera, deficiencia que sale a la luz gracias al hecho mismo de que en Magnesia no se instituya un modo de vida filosófico sino hasta el final de las Leyes ${ }^{18}$. La concepción que el

18 Benardete (1999) explica la cuestión mostrando que, en las Leyes, el automovimiento del alma nunca se pone en relación con el deseo erótico del alimento inteligible, "lo que realmente es", como en cambio sucede en Fedro, Banquete y República. Esta sería la diferencia más significativa entre Sócrates y el Extranjero Ateniense: "[En las Leyes] el mito socrático del Fedro ha sido legalizado y 
Extranjero Ateniense tiene del alma humana parece no exigir, por sí misma y desde el principio, la investigación filosófica. Dicha investigación es un efecto a posteriori de la legislación. Ahora bien, si el Extranjero no instituye sino hasta el final del diálogo un órgano político que cumpla la función de investigar la unidad de la virtud para perfeccionar las leyes es porque él mismo tampoco comprende sino hasta ese momento clave la profunda importancia de esta investigación para la vida humana, tema este que Sócrates, en agudo contraste con el Extranjero, no se cansará de examinar con sus interlocutores ${ }^{19}$. La deficiencia del alma tal como la concibe el Extranjero se cifra, entonces, en que no se trata de un alma jalonada en su búsqueda por el deseo erótico de la verdad; su deseo es artificial y utilitario, y aparece solo cuando su régimen político se muestra imperfecto y en peligro.

La aparición tardía de la filosofía en la institución del Consejo Divino tiene, pues, su raíz en la concepción del alma que se despliega en las Leyes. Ahora, mostrada dicha concepción a partir del análisis del mito de la marioneta y del libro 10, y habiendo constatado la dificultad que surge de la fundación de la ciudad sobre dicha concepción, puede plantearse en su sentido pleno la pregunta esbozada en la introducción de este ensayo: ¿por qué la filosofía, entendida como la investigación dialéctica de la unidad de la virtud, aparece tan solo al final del último libro de las Leyes, en lugar de ser un elemento operativo durante toda la fundación de la ciudad?

5. La imagen de la marioneta, el asombro y el principio de la filosofía

Para Responder la pregunta sobre el lugar de la filosofía en las Leyes, es necesario volver al principio del diálogo, a las inmediaciones del mito de la marioneta, donde el Extranjero Ateniense imagina una competencia entre los representantes de todos los géneros de entretenimiento de la Atenas clásica. En esta competencia vencería quien con su representación causara a los espectadores el

despojado de sus alas" (p. 38; traducción propia). ["[In the Laws] Socrates' myth of the Phaedrus has been legalized and stripped of its wings"] (p. 38).

19 Zuckert (2009, pp. 31-47) expone las diferencias entre Sócrates y el Extranjero Ateniense, argumentando que la filosofía, en todo el corpus platónico y no solo en los supuestos diálogos socráticos, se entiende sobre todo en los términos de la investigación socrática de la excelencia humana. 
mayor placer $(L .2,658 \mathrm{a}-659 \mathrm{a})^{20}$. Como es de esperarse, cada grupo de espectadores elegiría el espectáculo que fuera de su agrado, con lo cual la cuestión quedaría así: los ancianos darían por ganador a un rapsoda que recitara algunos versos épicos; la gran mayoría, contando adolescentes y mujeres, elegirían al que los conmoviera presentando una tragedia; los niños mayores elegirían una comedia; los niños más pequeños darían por ganador al que presentara un espectáculo de marionetas. Sorprendentemente, es la elección de los niños más pequeños de la ciudad la que proporciona la clave para responder la pregunta sobre la aparición tardía de la filosofía en las Leyes.

La imagen de la marioneta está relacionada con la mirada inocente del niño. Lo que determina esta relación es la capacidad que tiene el niño para ver una marioneta de un modo que es imposible para un joven o un adulto. Como el niño ignora los mecanismos que causan el movimiento de la marioneta, le parece que ella se mueve a sí misma y que tiene voz propia, es decir, que tiene alma. Esta ilusión de automovimiento, de vida, le genera al pequeño gran asombro. El asombro del niño es el punto clave. Según el Extranjero Ateniense, no sería "asombroso" (ou thaumaston) que alguno pensara que la forma más fácil de vencer en la contienda fuese ofrecer "un juego de marionetas" (thaúmata) (L. 2, 658b-c). Con esta frase el Extranjero indica de forma explícita una relación entre la imagen de la marioneta y el asombro ${ }^{21}$. La capacidad que tiene la marioneta para asombrar al niño está, por tanto, detrás de la elección de la palabra que se usa para designarla. ¿Qué significa esta relación entre la marioneta y el asombro?

Como cualquier niño llega a entender una vez perdida la inocencia de la mirada, la marioneta en realidad no se mueve a sí misma. Por eso resulta inquietante la comparación que en el mito de la marioneta se hace de nosotros, "seres vivos" (L. 1, 645d), con unos artefactos, inanimados por definición. Este es uno de los rasgos que le brinda eficacia a la imagen, la asombrosa conjunción del artefacto, que parece moverse a sí mismo, pero es movido por otro, con el alma,

20 Por el rol que en este pasaje juega la determinación de los géneros poéticos y de entretenimiento que se realiza a lo largo de las Leyes, Folch (2015) lo bautiza adecuadamente "la contienda (agôn de los géneros" (p. 189).

21 Kurke (2013, p. 124) ha elaborado con fineza las razones de esta relación en el contexto general de la cuestión del asombro como principio de la filosofía. 
que en efecto se mueve a sí misma, como también al artefacto. La imagen de la marioneta está constituida por la tensión entre los dos elementos comparados. Esta tensión revela las dos perspectivas desde las cuales puede observarse lo que se mueve a sí mismo. La perspectiva desde la cual el niño cae bajo la asombrosa ilusión del automovimiento es exterior; la marioneta parece moverse cuando es vista desde afuera. Análogamente, los otros seres humanos parecen moverse a sí mismos desde mi perspectiva exterior a ellos. ¿Cómo comprobar que tienen en sí su principio de movimiento, que no soy presa de una ilusión como la del niño que mira la marioneta y cree que vive?

$\mathrm{Al}$ no poder penetrar en los demás, el alma solo puede cumplir el movimiento reflexivo examinándose ella misma. La segunda perspectiva que podemos proyectar sobre el alma es, así, la interior. En virtud del asombro causado por la comparación del alma con un artefacto, la imagen de la marioneta invita al lector de las Leyes a llevar su atención de la aparente exterioridad del automovimiento a su propia interioridad, para examinar el alma tal como puede verla en sí mismo, desde una perspectiva de primera persona. Este es el movimiento representado en la misma marioneta cuando, escindida entre los impulsos no-racionales que luchan en su interior, ella examina su dinámica en busca de una forma de vida mejor que la actual.

Ahora bien, en los diálogos de Platón el movimiento reflexivo no consiste en un ensimismamiento cartesiano. La investigación solitaria del alma no es siquiera pensable porque, según la esencia del diálogo platónico, lo interior se revela siempre en comunidad; porque "la intimidad de la experiencia personal pasa de algún modo a través de un proceso de comunicación con otros" (Velásquez, 2013, p. 13). Aunque no se pueda penetrar en la interioridad de los demás, el descubrimiento de la propia interioridad se hace en un ámbito que no queda limitado a la subjetividad cerrada, y es por eso que el hilo de oro de la marioneta representa tanto el razonamiento como la "ley general de la ciudad" (L. 1 , 645a). La imagen entreteje la dimensión individual del autoconocimiento con la dimensión política, que será enfatizada en cambio en la investigación colegiada del Consejo Divino.

En las Leyes no se despliega el método que permita llevar a cabo la investigación del alma que queda puesta como tarea implícita en la imagen de la marioneta. El camino del conocimiento del alma es descubierto por el Extranjero 
solo a partir de la necesidad de conservar en el tiempo su régimen político, con la fundación del Consejo, y resulta no ser otro que la investigación dialéctica de la unidad de la virtud, es decir, la filosofía. La aparición de la filosofía en las Leyes responde a una necesidad política. Pero esta necesidad impone la tarea de la investigación del alma humana individual, al modo socrático, de manera que el desempeño político depende del conocimiento filosófico del alma. Esto quedaba ya dicho en el primer libro de la obra, donde el Extranjero Ateniense afirmaba que la tarea del político es cuidar las almas y que, en consecuencia, el político debe fijar su mirada sobre el alma para conocerla (L. 1, 650a).

Juntando los hilos del discurso, se revela que la fundación del órgano filosófico del Consejo Divino al final del diálogo corresponde a la imagen de la marioneta situada al principio. Comenzando con la asombrosa imagen de la marioneta y finalizando con la institución de la investigación dialéctica del Consejo, en las Leyes se dramatiza el nacimiento de la filosofía, poniendo en escena una penetración indirecta y progresiva en el conocimiento del alma humana, que tiene por principio el asombro causado por la imagen. Atendemos a un movimiento desde los plásticos estratos bajos del alma hacia el razonamiento, que hace su primera y tímida aparición en el libro 10. En su punto final, el camino recorrido por el Extranjero muestra la necesidad de comenzar la investigación desde el principio, como una segunda navegación emprendida con plena conciencia de la naturaleza escurridiza de lo buscado y por medio del método filosófico por excelencia, la dialéctica.

La ausencia casi total de la palabra filosofia en las Leyes no debe tomarse, entonces, por una ausencia de la filosofía misma. Se trata más bien de una suerte de presencia subterránea de la filosofía, que imanta la formación de lo no-racional del alma por medio de una educación ya orientada a partir de criterios filosóficos. A pesar de las diferencias entre ambas obras, el tipo humano que el Extranjero Ateniense busca moldear es, en este sentido bien determinado, comparable con los guardianes de la República, que, antes de su coronación matemática y dialéctica, reciben una larga educación musical y gimnástica muy parecida a la de los ciudadanos de las Leyes. Esta observación podría servir de base para un examen detallado del lugar que debería dársele a las Leyes en la interpretación del conjunto de los diálogos de Platón. Por lo pronto ha quedado un poco más claro el camino seguido por el anciano Extranjero en la fundación de Magnesia, 
camino que lo lleva a caer en cuenta de la necesidad de la filosofía y, con ello, a indicar un sendero ulterior que ya la vida no le iba a permitir recorrer.

\section{Referencias}

Altman, W. (2012). Plato the Teacher: The Crisis of the Republic. Plymouth: Lexington Books. DoI: 10.1111/1467-9752.12099

Benardete, S. (1999). Socrates and Plato: the Dialectics of Eros. München: Carl Friedrich von Siemens Stiftung.

Benardete, S. (2000). Plato's Laws. The Discovery of Being. Chicago: University of Chicago Press.

Brisson, L. \& J. F. Pradeau (2006). Notes. En: Platon. Les Lois, Livres I à VI. (Trad. L. Brisson \& J. F. Pradeau). Paris: Flammarion.

Flórez, A. (2012). El río torrencial de los argumentos: una lectura fenomenológicohermenéutica de Leyes X de Platón. Manuscrito inédito.

Folch, M. (2015). The City and the Stage: Performance, Genre, and Gender in Plato's Laws. Oxford: Oxford University Press. DoI: 10.1093/acprof:o so/9780190266172.001.0001

Fossheim, H. (2013). The Prooimia, Types of Motivation, and Moral Psychology. En: C. Horn (Comp.), Platon: Gesetze - Nomoi (pp. 87-104). Sankt Agustin: Akademia Verlag. Dor: 10.1524/9783050064482.87

Frede,D. (2010). Puppets on Strings: Moral Psychology in Laws Books 1 and 2.En: C. Bobonich (Ed.), Plato's Laws: A Critical Guide (pp. 108-126). Cambridge: Cambridge University Press. DOI: 10.1017/CBO9780511781483.007

Jorgenson, C. (2018). The Embodied Soul in Plato's Later Thought. Cambridge: Cambridge University Press. DoI: doi.org/10.1017/9781316795651

Klosko, G. (2006). The Development of Plato's Political Theory. Oxford: Oxford University Press.

Kurke, L. (2013). Imagining Chorality: Wonder, Plato's Puppets, and Moving Statues. En: A. Peponi (Ed.), Performance and Culture in Plato's Laws (pp. 123-160). Cambridge: Cambridge University Press. DoI: 10.1017/ CBO9781139061674 
Lin, Z. (2016). The Myth of the Soul in Plato's Laws. En: R. Benítez \& K. Wang (Eds.), Reflections on Plato's Poetics (pp. 191-202). Berrima: Academic Printing and Publishing.

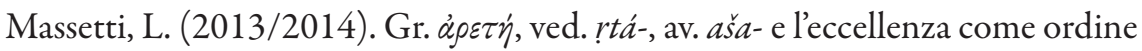
aggiustato. Münchener Studien zur Sprachwissenschaft, 67(2), 123-148.

Mayhew, R. (2008). Introduction. En: Plato. Laws 10 (pp. 1-11). (Trad. R. Mayhew). Oxford: Clarendon Plato Series.

Platón (1987). Diálogos II: Gorgias, Menéxeno, Eutidemo, Menón, Crátilo. (Trad. J. Calonge, E. Acosta, F. Olivieri \& J. Calvo). Madrid: Gredos. Platón (1988). Diálogos IV: República. (Trad. C. Eggers Lan). Madrid: Gredos. Platón (1992). Diálogos VI: Filebo, Timeo, Critias. (Trad. M. Ángeles Durán y F. Lisi). Madrid: Gredos.

Platón (1999). Las Leyes. (Trad. J. Pabón \& M. Fernández Galiano). Madrid: Centro de Estudios Políticos y Constitucionales.

Platón (2008). Diálogos III: Fedón, Banquete, Fedro. (Trad. C. García Gual, E. Lledó Íñigo \& M. Martínez Hernández). Madrid: Gredos.

Prauscello, L. (2013). Choral Persuasions in Plato's Laws. En: R. Gagné \& M. Govers Hopman (Eds.), Choral Meditations in Greek Tragedy (pp. 257-277). Cambridge: Cambridge University Press.

Russon, J. (2013). Education in Plato's Laws. G. Recco \& E. Sanday (Eds.), Plato's Laws: Force and Truth in Politics (pp. 60-74). Indianapolis: Indiana University Press.

Sassi, M. (2008). The Self, the Soul and the Individual in the city of the Laws. B. Inwood (Ed.), Oxford Studies in Ancient Philosophy, Volume XXXV (pp. 125-148). Oxford: Oxford University Press.

Sauvé-Meyer, S. (2015). Commentary. En: Plato. Laws 1 and 2 (pp 77-340). (Trad. S. Sauvé-Meyer). Oxford: Clarendon Plato Series.

Schöpsdau, K. (2011). Kommentar. En: Platon. Nomoi (Gesetze), Buch VII-XII (pp. 161-606). (Trad. K. Schöpsdau). Götingen: Vandenhoeck \& Ruprecht. Velásquez, O. (2013). Introducción. En: Platón. Alcibiades (pp. 11-49). (Trad. O. Velásquez). Santiago de Chile: Ediciones Tácitas.

Vergara, F. (1988). La Paideia Griega. Universitas Philosophica, 6(11-12), 153-168. 


\section{DIEGO GARCÍA RINCÓN}

Voegelin, E. (2000). The Laws. En: D. Germino (Ed.), Order and History, Volume III: Plato and Aristotle (pp. 269-324). Columbia: University of Missouri Press.

Zuckert, C. (2009). Plato's Philosophers: The Coherence of the Dialogues. Chicago: University of Chicago Press. 